\title{
Unique design features of the FAIMER Fellowship in Health Sciences Education
}

\author{
P Ravi Shankar \\ Department of Medical Education, KIST Medical College, Nepal.
}

\begin{abstract}
The Foundation for Advancement of International Medical Education and Research (FAIMER) promotes medical education and research internationally. In the last ten years regional institutes have been opened in India, Brazil and South Africa. The institutes offer health science educators a two year part-time fellowship in health science education and educational leadership. I have been associated with the program both as a fellow and a faculty. The program has a number of unique design features which has contributed to its success. In this article I share these features which can be considered by programs elsewhere.
\end{abstract}

Key words: Active learning, Curriculum innovation project, Developing countries, Faculty development, FAIMER 


\section{Introduction}

The Foundation for the Advancement of International Medical Education and Research (FAIMER) established in the year 2000 promotes medical education and research internationally (1). Over the last ten years, the organization has started regional centers in India, Brazil and South Africa. FAIMER offers health science educators a two year part-time fellowship in health sciences education and educational leadership. The program was initially offered at the FAIMER Institute in the United States (US) and the first year consists of two residential sessions before and after an intersession of distance learning and designing and implementing an educational project at the participant's home institution. The second year, completed from the Fellow's home country, involves co-mentoring a new Fellow and active engagement in the Institute's Internet discussion group (2). Modifications have been carried out in regional institutes.

I had completed the fellowship from the PSGFAIMER Regional Institute, Coimbatore, India in 2009 and have been associated as a faculty of the institute for the last two years. The fellowship has many inbuilt design features which ensure success. In this article I discuss these design features some of which have been mentioned briefly in a letter to the editor (3).

FAIMER identifies young, talented individuals with the potential to become change agents, organizes and delivers an effective learning intervention, facilitates the opportunity for real-life application of the knowledge in a supported environment and promotes development of a sustainable career path (4). The programs allow fellows to acquire skills in health science education, in leadership and management and create a strong community of practice and aims to slow migration of health education professionals (5).

\section{The selection process}

FAIMER selects applicants based on their teaching experience, their involvement in educational activities in the institution, publications in the field of health sciences education and the quality of a submitted curriculum innovation project (CIP). The CIP is designed and implemented in the fellow's home institution and support from the Principal or Dean to the project is an important criterion for selection. The CIP ensures the institution has a commitment towards the fellows program and benefits from the resulting innovation and changes.

\section{The first on-site session}

The first on-site session is held at the institute where the fellow has been selected. The duration varies from seven days in Indian institutes to 14 to 20 days in others. I feel the one week duration of the Indian program is insufficient and many interesting activities and sessions conducted in institutes elsewhere have to be either deleted or curtailed. The session starts with 'ice breaking' activities like introducing your partner and the game of crossing the river filled with crocodiles. The activity of filling in your partners details on the chart provided is a beautiful activity. The charts are preserved and when fellows come for the second on-site session next year they complete the chart. The main focus during the first on-site session is on the fellow's CIP. Fellow learn various techniques and improve their knowledge of leadership and consensual decision making skills with the objective of being able to implement their CIP successfully. This provides a strong motivation for the fellow to learn these skills. The afternoons are devoted to refining and developing the fellow's CIP 
based on inputs from the faculty and other fellows. The faculties are experts in the field of health sciences education and most of them have completed a FAIMER Fellowship or other advanced degrees in health sciences education. Fellows bring an outline of their CIPs to the session and first work on long term objectives of their project. They then develop medium and short term objectives. The thinking process starts from the 'bigger' perspective and is then narrowed down (6). Fellows usually work in groups of four with three or four faculty members.

Fellows develop 'indicators' which help them measure the 'progress' of their projects and decide whether they have achieved their objectives. The focus is on developing SMART objectives. SMART is an acronym for Specific, Measurable, Achievable, Realistic and Time bound. Fellows develop a concept map of their project which helps to concretize objectives, delineate different steps and clarify their links to one another. The program theory and concept map of the FAIMER program which is displayed serves as an excellent guide for fellows to develop their individual maps.

\section{Year 2 and graduating fellows and the first} year fellow's CIP

The second year fellows and the graduating fellows join the first years for the last twothree days of the program. These fellows can offer pertinent advice and support to the year 1 fellows just initiating their CIPs. As a faculty I have noticed their advice, queries and suggestions are pertinent and practical. The small groups are expanded to include year 2 and graduating fellows who join according to the subject area of their CIP.

There are close one to one semiformal interactions between year 1 and year 2 fellows. Also the graduating fellows talk in a group about their experiences of the FAIMER fellowship and the year 2 and 1 fellows listen quietly to the deliberations. The simple graduation ceremony of the fellows is watched with great interest by year 2 and year 1 fellows.

\section{The second on-site session}

The main focus during this session is on the presentation of the completed CIP and on interacting with and helping the year 1 fellows. Fellows bring a printed poster of their CIP. The poster presentations are conducted in a unique manner in small groups with posters being grouped together according to subject areas. The sixteen posters are grouped together in four groups. The year 2 fellows present their poster to the year 1 fellows who take notes and ask questions. The year 1 fellows then present the year 2 fellows poster to the larger group (6). Year 2 fellows develop the skill of presenting the gist of their poster to the year one fellows. Comments by graduating fellows and the faculty add to the richness and quality of the poster sessions.

The presentation is followed by a gallery walk led by the faculty where participants appreciate the good points about the design, layout and colors used in the poster and also provide constructive suggestions for improvement. The second year fellows also create a visual map of the future and present it to the larger group. The second year fellows conduct an eight to ten minute microteaching session using audiovisual aids of their choice. Participants submit their lesson plan at least two days in advance. The session is again conducted in four small groups. Participants are allowed to choose topics of their choice and are not restricted to health science subjects. The small group provides suggestions and constructive criticism. Based on these comments the group chooses the lesson plan of one of the fellows for're- 
planning'. The re-planned lesson plan is then presented to the large group. There are sessions on educational scholarship and fellows work on preparing an abstract of their CIP for submission to 'Really good stuff' in Medical Education or 'Out of the box' section in South-east Asian Journal of Medical Education'.

A study published in 2007 showed 23 percent of CIPs were directly related to community health (4). Of the 35 fellows in the first three classes of the Institute in the US, there have been 11 promotions, 9 peer-reviewed publications and 14 international poster presentations, indicating development of the medical education field.

\section{The FAIMER listserv}

The learning during the intersession period occurs through the FAIMER listserv. All fellows, alumni and faculty are members of the listserv. All institutes have their own listserv. The contacts made during the on-site sessions and personal interactions are maintained and sustained on the listserv. Discussions on various topics related to health sciences education are conducted each month. Two first year fellows moderate the discussion while two year 2 fellows guide the first years. Faculty also acts as facilitators for different topics. Alumni are also welcome to join the deliberations. The topics and facilitators are decided during the on-site sessions. At the end of the month the first year fellows submit a summary of the discussions and the second years submit a scholarly report of the month's deliberations.

Periodic monitoring of the fellows' progress occurs through the progress reports they submit. During the last month before the second on-site session fellows submit posters of their CIPs for comments and feedback from others. In addition to the scheduled discussion, other topics and concerns and personal issues could also be discussed on the listserv which serves as an important means of support for fellows, alumni and faculty. A study showed social e-mails constituted onethird of all e-mails in a regional institute listserv (7). These posts promote bonding between learners and contribute to better interaction and collaboration in online learning. Discussions have a conversational tone and follow a semi-structured format. The participants share their personal and professional experiences and the moderator 'wraps up' with a summary of the learning at the end of the month. Faculty facilitates the discussion, sharing appropriate resources and clarifying issues when needed (8).

\section{The environment of the on-site sessions:}

The on-site sessions are held at the Regional Institute and for most fellows and faculty this is a 'protected' time which they can fully devote to educational activities. The sessions are held in a comfortable environment. The accommodation and food are memorable creating sweet memories and friendships. The visiting faculty and fellows are usually lodged together deepening relationships. Good relationships develop between international faculty and regional faculty. FAIMER fellows and faculty have collaborated on projects strengthening health science education in the region.

These unique features have contributed to the success of the FAIMER program and can be considered by other distance education programs especially in the field of health science education. 


\section{Reference}

1. Afolabi B, Olapade-Olaopa EO. International training in medical education--the FAIMER institute 2002 fellowship experience. Afr J Med Med Sci. 2006; 35: 59-67.

2. Norcini J, Burdick W, Morahan P. The FAIMER Institute: creating international networks of medical educators. Med Teach. 2005; 27: 214-218. http://dx.doi.org/10.1080/014215905001 26379

3. Shankar PR, Bhandary S. FAIMER regional institutes: A positive direction in medical education. Med Teach. 2010;32:938-939.

4. Burdick WP, Morahan PS, Norcini JJ. Capacity building in medical education and health outcomes in developing countries: the missing link. Educ Health (Abingdon). 2007; 20:65.
5. Burdick WP, Morahan PS, Norcini JJ. Slowing the brain drain: FAIMER education programs. Med Teach. 2006; 28: 631-634. http://dx.doi.org/10.1080/014215906009 22883

6. Shankar PR. Being a faculty member at the PSGFAIMER regional institute. Clin Teach. (in press).

7. Anshu, Sharma M, Burdick WP, Singh $T$. Group dynamics and social interaction in a South Asian online learning forum for faculty development of medical teachers. Educ Health (Abingdon). 2010; 23: 311.

8. Anshu, Bansal P, Mennin SG, Burdick WP, Singh T. Online faculty development for medical educators: experience of a South Asian program. Educ Health (Abingdon). 2008; 21: 175.

Corresponding Author: Prof Dr P. Ravi Shankar, Department of Medical Education, KIST Medical College, P.O. Box 14142. Kathmandu, Nepal. Email: ravi.dr.shankar@gmail.com 